\title{
Microstructural Changes at the Initial Stage of Precipitation in an Aluminum-Silicon Alloy*
}

\author{
Keiyu Nakagawa ${ }^{1}$, Teruto Kanadani ${ }^{1}$, Laurence Anthony ${ }^{2}$ and Hatsujiro Hashimoto ${ }^{1}$ \\ ${ }^{1}$ Department of Mechanical Systems Engineering, Faculty of Engineering, Okayama University of Science, \\ Ridai-cho, Okayama 700-0005, Japan \\ ${ }^{2}$ School of Science and Engineering, Waseda University, Tokyo 169-8555, Japan
}

\begin{abstract}
In this study, we use a transmission electron microscope (TEM) to observe the microstructure of an Al-Si alloy from immediately after quenching to the initial stage of precipitation. Results reveal the presence of patches immediately after quenching that are thought to be Si clusters, and these are coherent with the $\{111\}_{\text {matrix }}$. At the initial stage of aging, Si crystals with a plate-like structure are observed, contradicting the round shape previously described. We propose that the Si clusters that appear immediately after quenching act as nuclei for the plate-like Si crystals. As the aging time increases, these increase in length and thickness, becoming thick plate-like Si phase precipitates.
\end{abstract}

(Received October 19, 2004; Accepted February 25, 2005; Published April 15, 2005)

Keywords: aluminum-silicon alloy, initial stage of precipitation, microstructure, transmission electron microscopy, plate-like silicon crystal

\section{Introduction}

Although Al-Si alloys are commonly used for light alloy casting, quenching followed by aging at a temperature of $473 \mathrm{~K}$ results in precipitation hardening. Previous research has suggested that although GP-zones are found in many $\mathrm{Al}$ alloys, they are not formed in an Al-Si alloy during the precipitation process from the supersaturated solid solution. Instead, only equilibrium $\mathrm{Si}$ phase precipitates are found. These have a diamond structure in a face-centered cubic lattice on the matrix.

Theoretical investigations of $\mathrm{Si}$ phase precipitates in an $\mathrm{Al}-\mathrm{Si}$ alloy suggest that during pre-aging at a temperature around $273 \mathrm{~K}$, vacancies and/or solute atoms form clusters, and the clusters affect the nucleation of Si phase precipitates successively appearing during aging at higher temperatures. ${ }^{1-3)}$ In particular, it is anticipated that the formation of Si phase precipitates is closely connected with the formation of excess vacancies due to quenching.

During the aging process, previous research has shown that as the Si phase precipitates grow to approximately $20 \mathrm{~nm}$ they have a round shape. However, further growth results in $\mathrm{Si}$ phase precipitates with a plate-like structure, ${ }^{4)}$ the $\{111\}_{\mathrm{Si}}$ of which is known to be formed parallel to $\{111\}_{\mathrm{Al}},\{100\}_{\mathrm{Al}}$, and $\left.\{110\}_{\mathrm{Al}}, 5,6\right)$ in the $\mathrm{Al}$ matrices.

Previous transmission electron microscope observations (TEM) have revealed the presence of micro-particles appearing at the initial stage of precipitation, and these are thought to be the clusters mentioned above. Also, at the initial stage of precipitation in an $\mathrm{Al}-\mathrm{Si}$ dilute alloy, in contrast to earlier research, GP-zones or solute atom clusters are thought to be formed. ${ }^{7-9)}$ However, details about the formation of the clusters are still unknown.

In this paper, we investigate the microstructure of an $\mathrm{Al}-$ 1.2 mass \% (hereafter mass \% is referred to as \%) Si alloy, from the formation of clusters immediately after quenching to the formation of equilibrium $\mathrm{Si}$ phase precipitates at the

*This Paper was Originally Published in Japenese in J. Jpn. Inst. Met. 67 (2003) 521-527 initial stage of precipitation. We use high resolution electron microscope (HREM) observations to investigate the size of the various formations, and the relationship between the formations and the matrix.

\section{Experimental Methods}

\subsection{Materials}

$\mathrm{Al}-1.2 \% \mathrm{Si}$ alloy ingots were cast by melting $99.99 \% \mathrm{Al}$ and $99.999 \% \mathrm{Si}$ in a high purity alumina crucible in air. The ingots obtained ( $150 \mathrm{~mm}$ in length, $15 \mathrm{~mm}$ in diameter) were then homogenized by annealing at $823 \mathrm{~K}$ for $180 \mathrm{ks}$, peeled mechanically, and hot forged and cold rolled with intermediate annealing to produce strips of $0.2 \mathrm{~mm}$ or $1.1 \mathrm{~mm}$ thickness. These strips were used to prepare observation specimens.

\subsection{Heat treatment}

Heat Treatment was performed at $853 \mathrm{~K}\left(T_{\mathrm{Q}}\right)$ for $3.6 \mathrm{ks}$, followed by quenching to $273 \mathrm{~K}$ in ice-water. Next, the specimens were pre-aged in the ice-water bath for $60 \mathrm{~s}$ and then exposed to aging for various times $\left(t_{\mathrm{A}}\right)$ in a silicon oil bath held at $473 \mathrm{~K}\left(T_{\mathrm{A}}\right)$ The accuracy of $T_{\mathrm{A}}$ was $\pm 0.5 \mathrm{~K}$. After the treatment, the specimens were stored in liquid nitrogen.

\subsection{Transmission electron microscope (TEM) observa- tions}

For the electron microscope observations, the $0.2 \mathrm{~mm}$ thick strips were treated under various aging conditions, and then disks of $3 \mathrm{~mm}$ in diameter were cut from the strips. These disks were twin-jet polished using a solution kept at $263 \mathrm{~K}$ to prepare the specimens. The specimens were kept in ethanol at approximately $273 \mathrm{~K}$ until inserted into an electron microscope. Then, the specimens were maintained at room temperature for about $1.8 \mathrm{ks}$ until starting the TEM observations.

The present TEM observations were carried out using either a JEM-2000EX operated at $200 \mathrm{kV}$, or a JEM-4000EX at $400 \mathrm{kV}$. Structure observations from the initial stage of 
precipitation, and size measurements were carried out on the (110) and (100) faces of the specimens, where fine, uniformly distributed $\mathrm{Si}$ phase precipitates were identified on the $\{111\}_{\text {matrix }}$ and $\{100\}_{\text {matrix }}$ planes of the specimens. For image pattern contrast regions at the initial stage of precipitation, selected area diffraction techniques were used to determine whether or not these were image parallel Moiré pattern contrast regions (hereafter, Moiré regions), and the following formula was used to determine whether precipitates were formed,

$$
d_{\mathrm{m}}=d_{(111) \mathrm{M}} \cdot d_{(111) \mathrm{P}} /\left(d_{(111) \mathrm{P}}-d_{(111) \mathrm{M}}\right)
$$

where $d_{\mathrm{m}}$ is the width between Moire patterns, $d_{(111) \mathrm{M}}$ is the distance to the (111) planes of the matrix, and $d_{(11) \mathrm{P}}$ is the distance to the (111) planes of precipitates, which are parallel to the $(111)_{\text {matrix }}$. The values of $d_{(111) \mathrm{P}}$ were determined for $d_{(111) \mathrm{M}} \sim d_{(111) \mathrm{Al}}=0.233 \mathrm{~nm}$.

During high voltage electron microscope observations operated at $500 \mathrm{kV}$, the increase of a dislocation loop of $40 \mathrm{~nm}$ was observed when the target alloy was exposed to electron radiation for $30 \mathrm{~min}^{10}{ }^{10}$ Therefore, in all present HREM observations, the effects of the irradiation were considered, and we were careful to ensure no dislocation loops due to the irradiation were created by completing observations in $0.6 \mathrm{ks}$.

\section{Experimental Results and Discussion}

Figure 1 shows the results of electron microscope observations of a specimen solid solution treated at $853 \mathrm{~K}$ for $3.6 \mathrm{ks}$ immediately after quenching to $273 \mathrm{~K}$ in an ice-water bath. In other words, Fig. 1 shows the microstructure of a specimen during the pre-aging stage. Fig. 1(a) shows a low magnification micrograph in which a dislocation that is thought to be a result of quenching can be seen, together with microscopic patches (indicated by white arrows). Figure 1(b) shows a high resolution micrograph of the patches. In all the patches, a small area with dark contrast ${ }^{11)}$ of less than $5 \mathrm{~nm}$ size (indicated by arrows) can be observed parallel to the $\{111\}_{\text {matrix }}$. It is also noted that in the selected area diffraction pattern in Fig. 1(b), no streaks resulting from the formation of the GP zone and diffraction spots indicating secondary phases can be seen.

Although the results above give us information about the size and direction of the small areas with dark contrast observed in the high resolution micrograph, there is still a great deal about them that is unknown. On the other hand, in previous work we investigated the structure of small areas with dark contrast parallel to the $\{111\}_{\text {matrix }}$ of specimens during pre-aging for $950 \mathrm{ks}$ at $273 \mathrm{~K}$. The size of the small areas with dark contrast increased with increasing $t_{\mathrm{A}}$. We proposed that they were some kind of Si clusters that served as either the initial stage of precipitation of $\mathrm{Si}$ phase precipitates, or the nucleation sites for precipitation. ${ }^{12)}$ From these earlier results, we propose that the small areas with dark contrast observed in the present work are also $\mathrm{Si}$ clusters (hereafter clusters) that include vacancies.

To investigate the relationship between the clusters that form immediately after quenching and the formation of $\mathrm{Si}$ phase precipitates during the aging process, we observed the microstructure of specimens aged for very short times. Figure 2(a) shows a bright-field image of a specimen that was pre-aged and then aged for $10 \mathrm{~s}$ at $473 \mathrm{~K}$. It can be seen that the patches are less than $5 \mathrm{~nm}$ in diameter (shown by arrows). Figure 2(b) shows a high resolution micrograph of the patches, in which the small areas with dark contrast can again
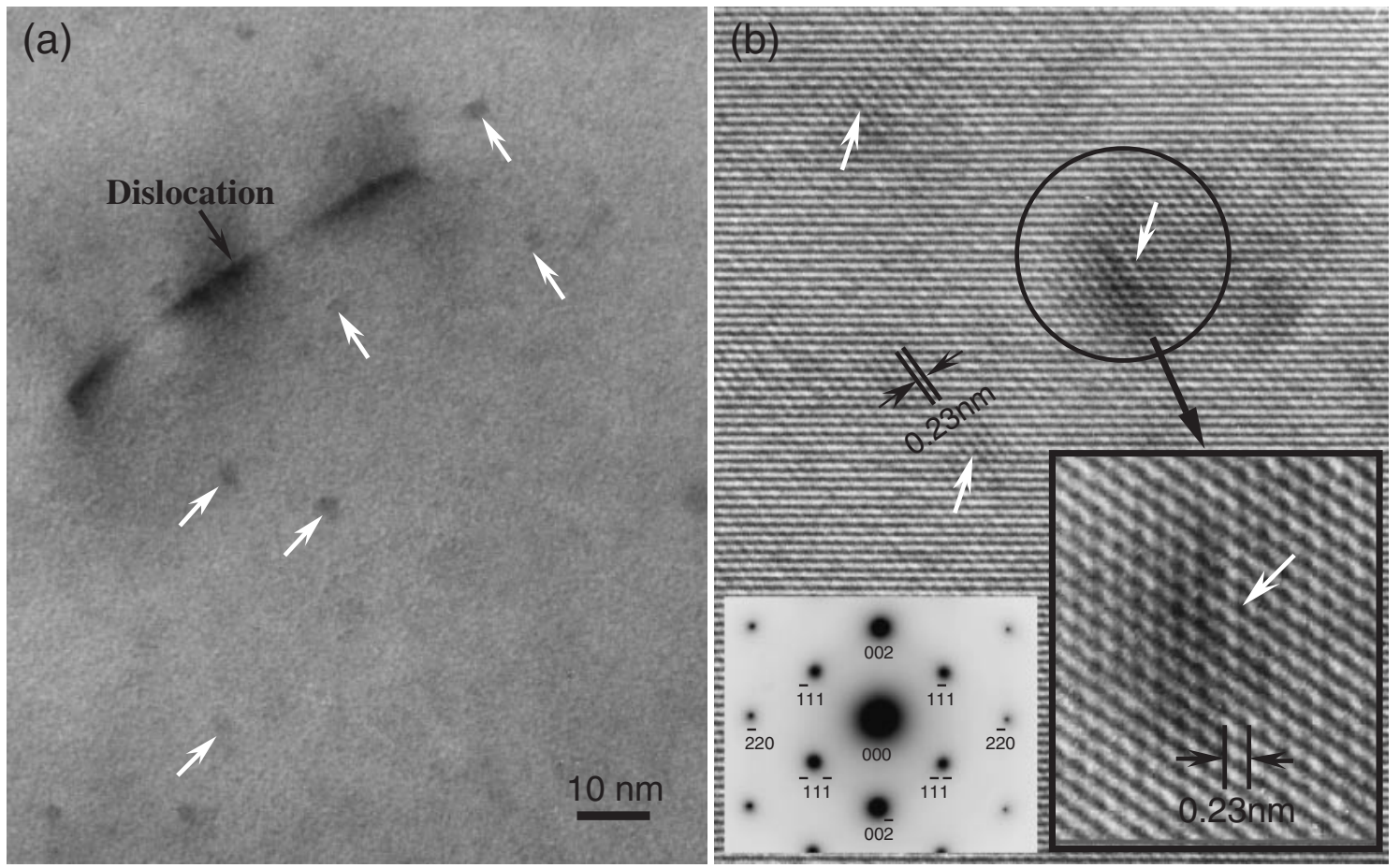

Fig. 1 Transmission electron micrographs of a specimen immediately after quenching from 853 to $273 \mathrm{~K}$. (a) Low magnification micrograph (b) High resolution micrograph. 

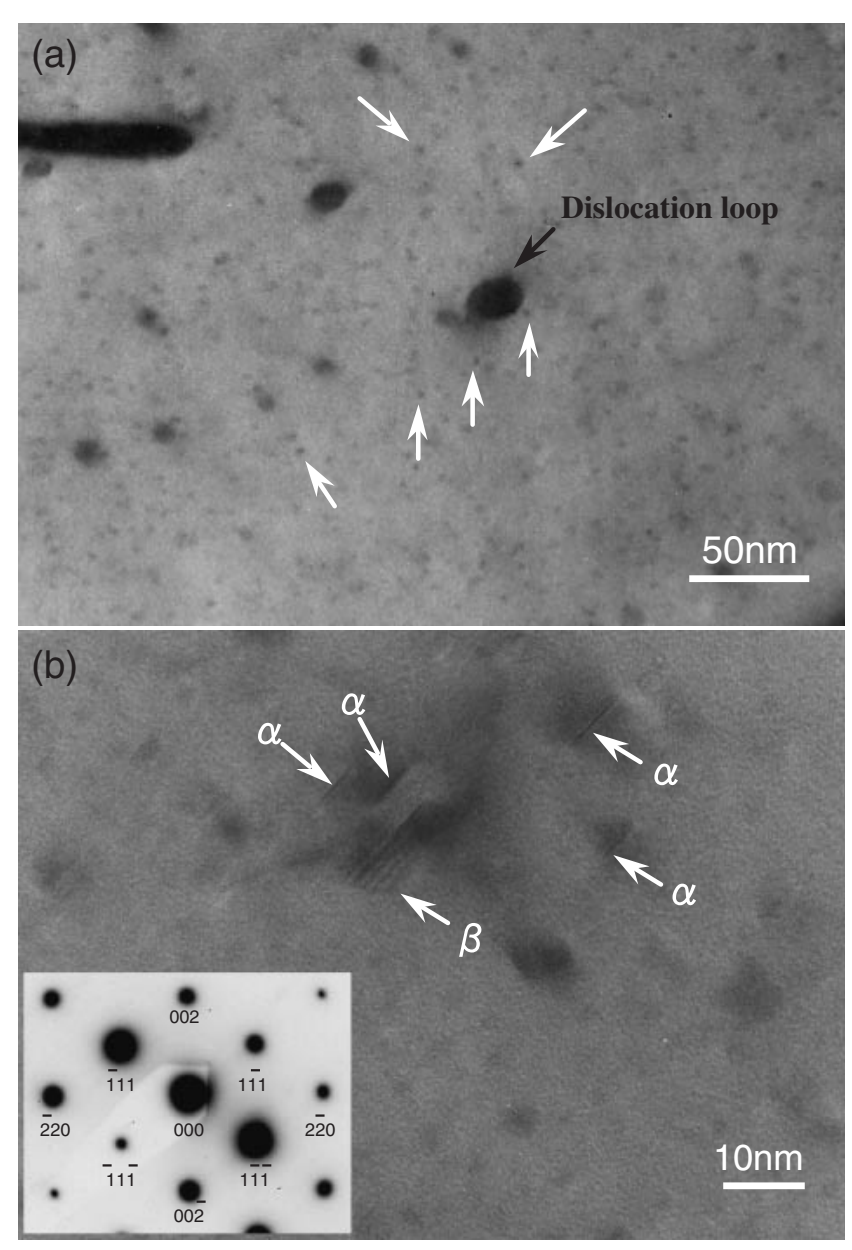

Fig. 2 Transmission electron micrographs of a specimen aged for $10 \mathrm{~s}$ at $473 \mathrm{~K}$ after quenching from 853 to $273 \mathrm{~K}$. (a) Low magnification micrograph (b) High resolution micrograph.

be seen. Also, a Moiré region $(\beta)$ can be seen in part of one of the patches. The average sizes of the small areas with dark contrast and Moiré regions are $4.6 \mathrm{~nm}$ and $4.3 \mathrm{~nm}$, respectively, and the values are comparable.

Figure 3 shows a high resolution micrograph in which a small area with dark contrast and the Moiré region from the sample used to produce Fig. 2 are clearly observed. The orientation of the small area with dark contrast $(\alpha)$ to the matrix is parallel in $\{111\}_{\mathrm{Al}}$, and the atomic arrangement of the interface between the small area with dark contrast and the matrix closely corresponds with the arrangement of the matrix. Therefore, the small area with dark contrast and the matrix are coherent. The distance between two neighboring atoms in the small area with dark contrast is shorter than that for $\{111\}_{\mathrm{Al}}$, and a distorted region exists in the vicinity of the interface between the small area with dark contrast and the matrix. Therefore, it can be concluded that Si precipitates are formed in the small area with dark contrast.

To measure the distance between patterns in the Moiré region, a selected area diffraction image of the small area with dark contrast and the Moiré region was generated (Fig. 3 inset). The image shows the following features: (1) Along the vector from the 000 spot to the diffraction point on the $\{111\}_{\text {matrix }}$, a weak extra spot with a $\{111\}_{\text {Si }}$ planeinterval distance diffraction point is observed (arrow 1). (2) A

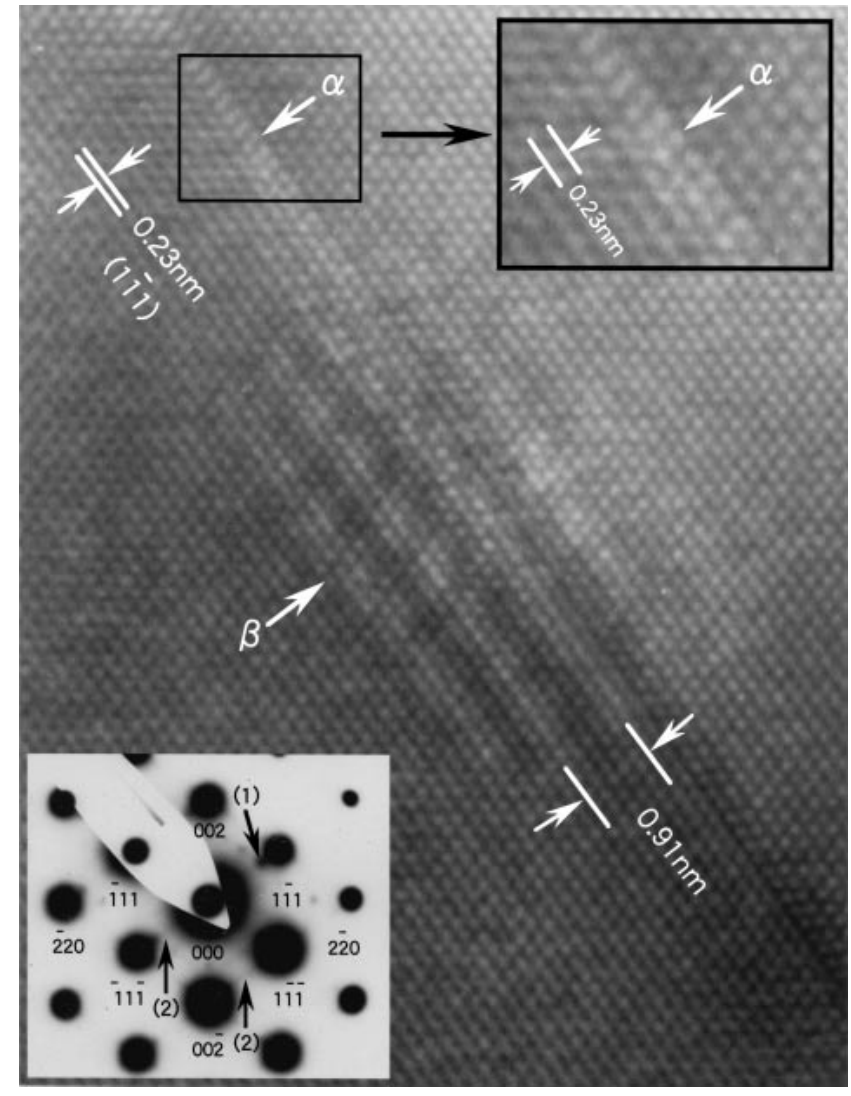

Fig. 3 High resolution micrograph of a specimen aged for $10 \mathrm{~s}$ at $473 \mathrm{~K}$ after quenching from 853 to $273 \mathrm{~K}$. Small area with dark contrast $(\alpha)$ and moiré region $(\beta)$ can be seen.

streak is observed in the $\langle 111\rangle$ direction on the $\{111\}$ diffraction point (arrow 2). From the result (1), we propose that the Moiré region is a parallel Moiré matrix pattern formed from $\{111\}_{\mathrm{Al}}$ and $\{111\}_{\mathrm{Si}}$. From the result (2), we propose that the precipitates formed in this region have a thin plate-like structure, and there is a distorted area in the $\langle 111\rangle$ direction of the $\mathrm{Al} .{ }^{13)}$ For the Moire region, the distance between the patterns was measured to be $0.91 \mathrm{~nm}$. Therefore, $d_{(111) \mathrm{M}}$ was taken to be $0.23 \mathrm{~nm}$, which is the surface interval distance of the $\{111\}_{\mathrm{Al}}$, and $d_{(11) \mathrm{P}}$ was measured to be $0.31 \mathrm{~nm}$. This is consistent with the $\{111\}_{\mathrm{Si}}$ surface interval distance of $0.31 \mathrm{~nm}$. From the above results, it is concluded that Si precipitates are also formed in the Moiré region.

In general, the main factor that affects the shape of precipitates during precipitation is the strain energy between the matrix and precipitates, or the interface energy. When the precipitates are coherent with the matrix such as a GP-zone, the size difference of the atomic radii of the matrix and solute elements has a large influence on the shape of the precipitates. On the other hand, when the precipitates and matrix are incoherent, the precipitates are influenced by the interface energy and they tend to have a round-shaped structure. ${ }^{14)}$ In previous studies on the precipitation process of an Al-Si alloy, only the formation of equilibrium Si phase precipitates was reported, without the formation of a GPzone. However, the results observed in this study show that in both the small area with dark contrast and the Moiré regions, there exists plate-like Si crystals ${ }^{15)}$ of several atoms thick- 
ness. We propose that the small area with dark contrast and Moiré regions are the edge and surface face of the Si crystals, respectively. For this reason, the average size of the streak regions and Moiré regions are approximately the same. Also, we observe areas where the small areas with dark contrast and $\{111\}_{\mathrm{Al}}$ are coherent with each other at an aging time of $10 \mathrm{~s}$. For this reason, in the same way that a GP-zone which is coherent with the matrix is formed in an $\mathrm{Al}-\mathrm{Cu}$ alloy, ${ }^{16)}$ we propose that as the $\mathrm{Si}$ crystals grow, there is reduction in distortion energy, which leads to the formation of plate-like Si phase precipitates.

Considering the lattice constants of $\mathrm{Al}$ and $\mathrm{Si}$, the difference in the atomic radii is approximately $4.3 \%$. This value is large compared with the values for $\mathrm{Al}-\mathrm{Zn}^{17)}$ and $\mathrm{Al}-$ $\mathrm{Ag},{ }^{18)}$ which form round-shaped GP-zones at the initial stage of precipitation. Even in Al, which has a relatively small elastic anisotropy, precipitates that form the surrounding distortions precipitate along the direction parallel to the smallest elastic anisotropy of the matrix with the largest direction of distortion. These precipitates have the tendency to be formed in a plate-like structure on the $\{111\}_{\text {matrix }}$ and $\{100\}_{\text {matrix }}$ reducing the anisotropy constant, which in turn reduces the anisotropy energy. For the alloy under investigation, the equilibrium $\mathrm{Si}$ phase precipitates that are precipitated during aging become coherent, ${ }^{3)}$ and the $\{111\}_{\text {matrix }}$ is one of the preferred crystallographic planes in the precipitation.

For Si crystals, the size at which the matrix Al can preserve coherence is still unknown. On the other hand, for Si crystals that have a very thin plate-like structure as examined in the present investigation, we propose that there are mixed regions showing coherence and incoherence in the interface between the small areas with dark contrast and the matrix. In other words, it is possible that there is partial coherence. From the above results, the patches observed at low magnification immediately after quenching in Fig. 1(a) are clusters. However, the patches observed at low magnification for specimens aged for $10 \mathrm{~s}$ at $473 \mathrm{~K}$ in Fig. 2(a) show the edges or surfaces of plate-like Si crystals.

Figure 4 shows a transmission electron microscope image of a specimen aged for $20 \mathrm{~s}$ at $473 \mathrm{~K}$. For aging times of $20 \mathrm{~s}$, plate-like $\mathrm{Si}$ crystals are formed on the $\{111\}_{\text {matrix }}$. The average size of these is $5.7 \mathrm{~nm}$. Although we investigated if there was an increase in thickness of the Si crystals, this could not be confirmed in the experiments performed.

Figure 5 shows the results of HREM observations of specimens aged for $180 \mathrm{~s}$ at $473 \mathrm{~K}$. Plate-like Si phase precipitates are formed on the $\{111\}_{\mathrm{Al}}$. The area marked (A) in the figure shows the surface of a plate-like $\mathrm{Si}$ phase precipitate, and the area marked (B) shows the edge of the plate-like Si phase precipitate. The average length of the plate-like Si phase precipitates was $6.0 \mathrm{~nm}$, and the average thickness was $1.7 \mathrm{~nm}$. Therefore, the structure changes from plate-like Si crystals to plate-like $\mathrm{Si}$ phase precipitates with a diamond structure as $t_{\mathrm{A}}$ increases.

\section{Conclusions}

In this paper, we have investigated the microstructure of an $\mathrm{Al}-1.2 \% \mathrm{Si}$ alloy from immediately after quenching to the

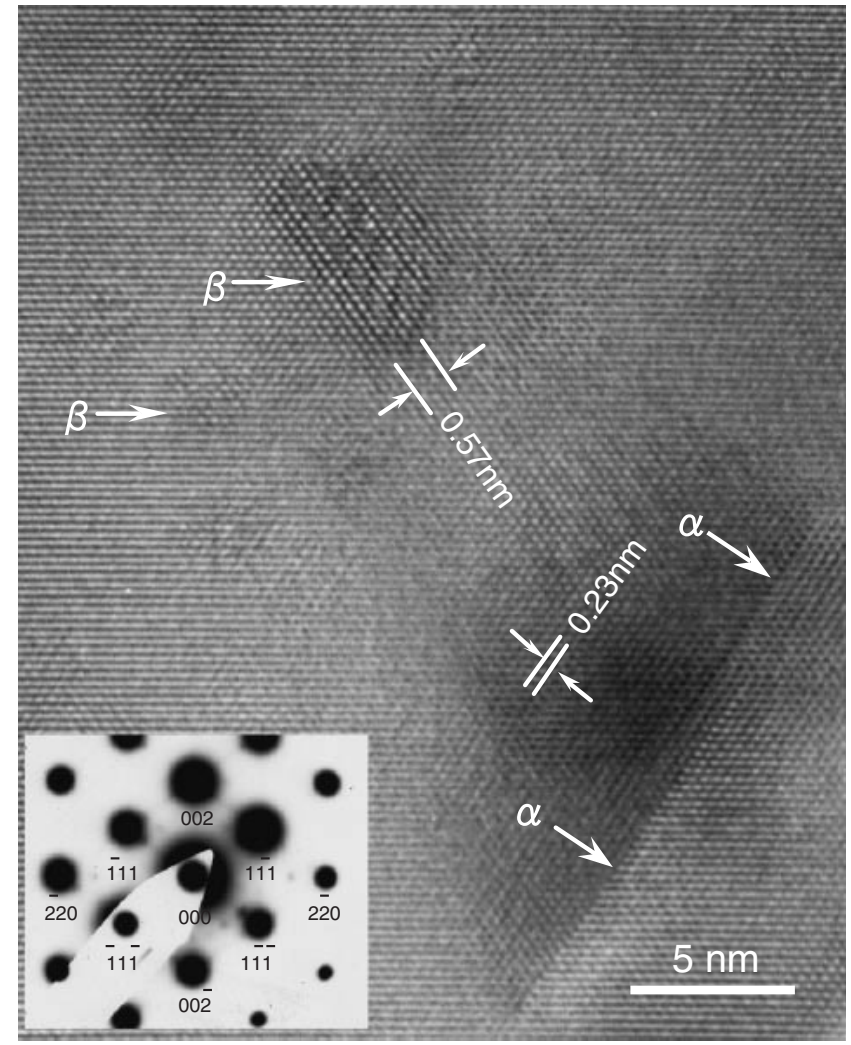

Fig. 4 High resolution micrograph of a specimen aged for $20 \mathrm{~s}$ at $473 \mathrm{~K}$ after quenching from 853 to $273 \mathrm{~K}$. Small area with dark contrast $(\alpha)$ and moiré region $(\beta)$ can be seen.

initial stage of precipitation. We also determined the size and directional relationship to the matrix, and clarified the following points.

(1) Immediately after quenching, clusters are formed with a size less than $5 \mathrm{~nm}$, in a parallel direction to $\{111\}_{\mathrm{Al}}$. These are coherent with the Al matrix.

(2) At short aging times $\left(t_{\mathrm{A}}=10-20 \mathrm{~s}\right)$, plate-like $\mathrm{Si}$ crystals are formed in $\{111\}_{\mathrm{Al}}$. It is thought that these are partially coherent with the matrix.

(3) From (1) and (2), we propose a model that the clusters appearing at the immediate start of the precipitation stage act as nuclei for the formation of the plate-like $\mathrm{Si}$ crystals.

(4) For aging times above $20 \mathrm{~s}$, plate-like $\mathrm{Si}$ phase precipitates are observed in $\{111\}_{\mathrm{Al}}$, and the average length and size of these increase with increasing $t_{\mathrm{A}}$.

\section{Acknowledgements}

The authors would like to express their gratitude to Professor E. Sukedai, Dept. of Mechanical Systems Engineering, Faculty of Engineering, Okayama University of Science, for assistance during the electron microscope observations, and Professor Y. Yokota, Research Institute of Natural Sciences, Okayama University of Science, for his valuable support. Also, we are sincerely grateful to Professor K. Nakai, Dept. of Materials Science and Engineering, Faculty of Engineering, Ehime University, and Professor B. Jouffery, École Centrale Paris, for valuable suggestions. 

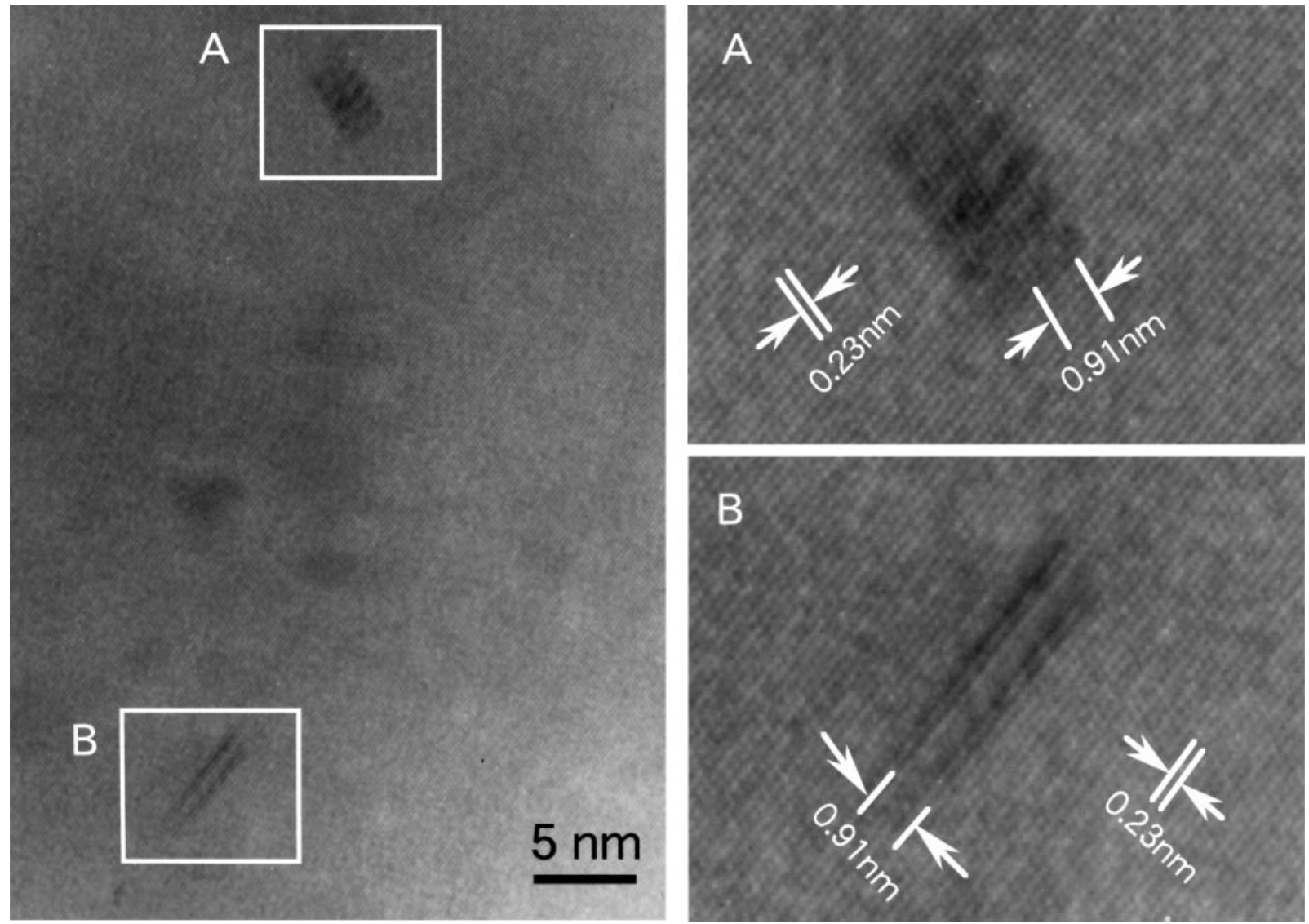

Fig. 5 High resolution micrograph of a specimen aged for $180 \mathrm{~s}$ at $473 \mathrm{~K}$ after quenching from 853 to $273 \mathrm{~K}$. Moiré region (A) and (B) can be seen. Moiré region (A) shows surface face of a plate-like Si precipitate. Moiré region (B) shows edge of a plate-like Si precipitate.

\section{REFERENCES}

1) H. S. Rosenbaum and D. Turnbull: Acta Metall. 6 (1958) 653-659.

2) E. Ozawa and H. Kimura: Acta Metall. 18 (1970) 995-1004.

3) H. Suzuki, M. Kanno, G. Itoh and K. Itoi: J. Jpn. Inst. Met. 46 (1982) 78-84.

4) M. Nemoto and S. Koda: J. Jpn. Inst. Met. 29 (1965) 399-405.

5) H. S. Rosenbaum and D. Turnbull: Acta Metall. 7 (1959) 664-674.

6) A. Saulnier: Mem. Sci. Rev. Met. 58 (1961) 615-625.

7) T. Kittaka: J. Sci. Hiroshima Univ., Ser. A-II. 32 (1968) 51-58.

8) J. Takamura: Lattice Defects in Quenched Metals, ed. R. M. Cotterill, (Academic Press, New York, 1965) 521-576.

9) T. Kanadan and K. Nakagawa: J. Jpn. Inst. Light Met. 46 (1996) 342 343.

10) M. Nemoto, T. Oguchi and H. Suto: J. Jpn. Inst. Met. 35 (1971) 886891.
11) The small areas with dark contrast are a change in contrast in the high resolution micrograph, with a characteristic thin, bright area that is used to determine their orientation.

12) K. Nakagawa, T. Kanadani, N. Hosokawa and T. Tanimoto: Phys. Status Solidi A 157 (1996) K1-K4.

13) P. B. Hirsch, A. Howei, R. B. Nicholson, D. W. Pashley and M. J. Whelan: Electron Microscopy of Thin Crystals, (Robert E. Krieger Publishing Co. Inc., Huntington, New York, 1977) pp. 317-351.

14) F. R. N. Nabarro: Proc. Phys. Soc. 52 (1940) 90-104.

15) For Si crystals, although the $\mathrm{Si}$ atoms do not form a perfect diamond structure, a face is formed with a $\mathrm{Si}$ atom lattice. In contrast, for $\mathrm{Si}$ phase precipitates there is an accumulation of more than one layer of unit cells with diamond structure.

16) R. B. Nicholson and J. Nutting: Philios Mag. 3 (1958) 531-535.

17) W. Mertz and V. Gerold: Z. Metallkd. 57 (1966) 607-615.

18) R. B. Nicholson and J. Nutting: Acta Metall. 9 (1961) 332-343. 